\title{
Microstructure and mechanical properties of HR6W alloy dedicated for manufacturing of pressure elements in supercritical and ultra- supercritical power units
}

\author{
Grzegorz Golański ${ }^{1 *}$, Agata Merda ${ }^{1}$, Adam Zieliński ${ }^{2}$, Paweł Urbańczyk ${ }^{3}$, Jacek Słania ${ }^{4}$, \\ and Milena Kierat $^{5}$ \\ ${ }^{1}$ Czestochowa University of Technology \\ ${ }^{2}$ Institute for Ferrous Metallurgy in Gliwice \\ ${ }^{3}$ Office of Technical Inspection, Katowice Branch, Dabrowa Gornicza Office \\ ${ }^{4}$ Institute of Welding Technology in Gliwice \\ ${ }^{5}$ Silesian University of Technology in Katowice
}

\begin{abstract}
The article presents the results of research on the microstructure and selected mechanical properties of HR6W nickel-base alloy. The test alloy was subjected to isothermal ageing at $700^{\circ} \mathrm{C}$ and for up to $10000 \mathrm{~h}$. The tests of the HR6W microstructure were performed using the scanning electron microscopy (SEM) and the transmission electron microscopy (TEM). The performed microstructural tests of the HR6W alloy showed that in the as-received condition it was characterised by the structure of nickel austenite with numerous primary precipitates of $\mathrm{NbC}$ and TiN. Ageing of the investigated alloy contributed to the precipitation of numerous particles of varying morphologies inside the grains and at the grain boundaries, as well as at the boundaries of twins - they were the secondary precipitates of $\mathrm{M}_{23} \mathrm{C}_{6}$ and Laves phase. The number of the particles precipitated at the boundaries was so large that they formed the so-called continuous grid of precipitates. Inside the grains, the presence of compound complexes of precipitates was observed. These complexes consisted of the TiN particles, as well as the $\mathrm{M}_{23} \mathrm{C}_{6}$ carbides and Laves phase nucleating on them. The tests of the mechanical properties of HR6W alloy showed that in the as-received condition the alloy showed high plastic properties, with relatively low strength properties - in particular, the yield strength. Ageing of the HR6W alloy, as a result of precipitation of numerous particles in the matrix, through the strengthening with the precipitation mechanism, resulted in a considerable growth of the strength properties - inter alia the yield strength by over $60 \%$, with the reduction of the plastic properties - elongation decreased by around $40 \%$. Similar growth in the test alloy was observed for hardness.
\end{abstract}

\footnotetext{
${ }^{*}$ Grzegorz Golański: grisza@,wip.pcz.pl
} 


\section{Introduction}

A strong tendency to increase steam temperature and pressure in coal-fired power units in order to improve their efficiency requires the use of modern high-temperature creepresistant materials for critical components operating under extreme temperature and stress conditions. These materials should have high creep resistance at high structural stability as well as high steam oxidation resistance and combustion gas corrosion resistance. One of the new materials that are being implemented in the energy industry as a material for supercritical boilers is the $23 \mathrm{Cr}-45 \mathrm{Ni}-6 \mathrm{IN}-\mathrm{Nb}-\mathrm{Ti}-\mathrm{B}$ (HR6W) nickel-base alloy. This alloy was developed in Japan as a material for components operating at $700 \div 800^{\circ} \mathrm{C}$. At present, the HR6W alloy is mainly recommended for thick-walled structural components such as primary steam pipelines or chambers. Mechanical properties of the HR6W alloy, i.e. creep resistance and stability of microstructure at above $650^{\circ} \mathrm{C}$, are comparable to those of the nickel-base superalloy referred to as Alloy 617 [1,2]. The chemical composition of the HR6W alloy was selected so that its strengthening is provided by tungsten atoms (solution strengthening) and Laves-phase precipitates (precipitation strengthening). This ensures a relatively high creep resistance - the extrapolated creep resistance at $700^{\circ} \mathrm{C}$ for $100,000 \mathrm{~h}$ is approximately $88 \mathrm{MPa}$ and for $750^{\circ} \mathrm{C}-64 \mathrm{MPa}$. Due to high chromium content of approx. $23 \%$, this alloy is characterised by better steam oxidation and hot corrosion resistance than ferritic steels [2, 3]. Therefore, because of its performance, the HR6W alloy is an intermediate construction material between austenitic steels and nickel superalloys. The suitability of creep-resistant steels and alloys for use in power unit system components is determined by labour- and time-consuming testing of minimum stability of microstructure and mechanical properties during annealing/ageing at a temperature similar to that of the expected service. The obtained test results are the basis for development of materials characteristics which are used in the industrial operations for assessing the condition of materials for power boiler components. To properly assess the material condition, the knowledge of long-term effect of temperature on changes in microstructure and mechanical properties is used. In creep-resistant ferritic steels and austenitic alloys, precipitation processes of secondary phases and changes in their morphology have a decisive impact on service life of the materials [4-8]. The aim of the research was to analyse precipitation processes and changes in mechanical properties in HR6W alloy subjected to isothermal ageing at $700^{\circ} \mathrm{C}$ for $10000 \mathrm{~h}$. 


\section{Material and research methodology}

The $23 \mathrm{Cr}-45 \mathrm{Ni}-6 \mathrm{IN}-\mathrm{Nb}-\mathrm{Ti}-\mathrm{B}$ (HR6W) creep-resistant nickel-base alloy was subjected to isothermal ageing at $700^{\circ} \mathrm{C}$ for $10,000 \mathrm{~h}$. The chemical composition of the test material is presented in Table 1.

Table 1. Chemical composition of HR6W alloy, wt. \%:

\begin{tabular}{|c|c|c|c|c|c|c|c|c|c|}
\hline $\mathbf{C}$ & $\mathbf{S i}$ & $\mathbf{M n}$ & $\mathbf{P}$ & $\mathbf{S}$ & $\mathbf{C r}$ & $\mathbf{W}$ & $\mathbf{T i}$ & $\mathbf{N b}$ & $\mathbf{N i}$ \\
\hline 0.10 & 1.00 & 1.50 & 0.01 & 0.01 & 21.50 & 7.00 & 0.20 & 0.35 & 45.00 \\
\hline
\end{tabular}

The performed tests included:

- analysis of microstructure using JEOL JSM-6610LV scanning electron microscope, the structural tests were performed on ferric chloride-etched metallographic microsections,

- identification of precipitates by selective electron diffraction using Titan 80-300 transmission electron microscope,

- $\quad$ strength property tests including: static tensile test at room temperature using Zwick/Roel Z100 tensile testing machine and hardness measurement with an indenter load of $10 \mathrm{kG}(98.1 \mathrm{~N})$ using Future Tech FV-700 Vickers hardness testing machine.

\section{Research results and analysis}

\subsection{Microstructure of test alloy in the as-received condition}

The HR6W nickel-base alloy in the as-received condition is delivered after solution heat treatment. The solution heat treatment of the test alloy is carried out at $1190-1250^{\circ} \mathrm{C}$ and followed by water cooling [3]. The solution heat treatment is to ensure a homogeneous structure of nickel austenite with no precipitates. In the HR6W alloy structure, numerous annealing twins are visible (Fig. 1), which is characteristic of alloys with an A1 lattice characterised by low stacking fault energy. The test material grain size was $2-4$ according to ASTM standard scale. The test alloy includes in its chemical composition strong carbideforming alloying elements, i.e. titanium and niobium, and therefore, in its microstructure in the as-received condition, numerous primary precipitates of micrometric size are observed in the nickel austenite matrix. Two types of morphology of the primary precipitates were revealed in the test alloy: globular-like particles and rectangular particles. The globular precipitates were rich in niobium, while the rectangular particles were rich in titanium. The identifications revealed that the first of them was $\mathrm{NbC}$ precipitates, while the latter was TiN precipitates (Fig. 2). Some of the TiN particles precipitated by nucleating heterogeneously on $\mathrm{Al}_{2} \mathrm{O}_{3}$ oxides. The primary precipitates in creep-resistant austenitic alloys are unfavourable because cracking may occur on their precipitate/matrix interfaces when creeping [9]. The primary precipitates in the structure of the test alloy mainly occurred inside the austenite grains, and some of these particles were observed near and at the grain boundaries (Fig. 1). 


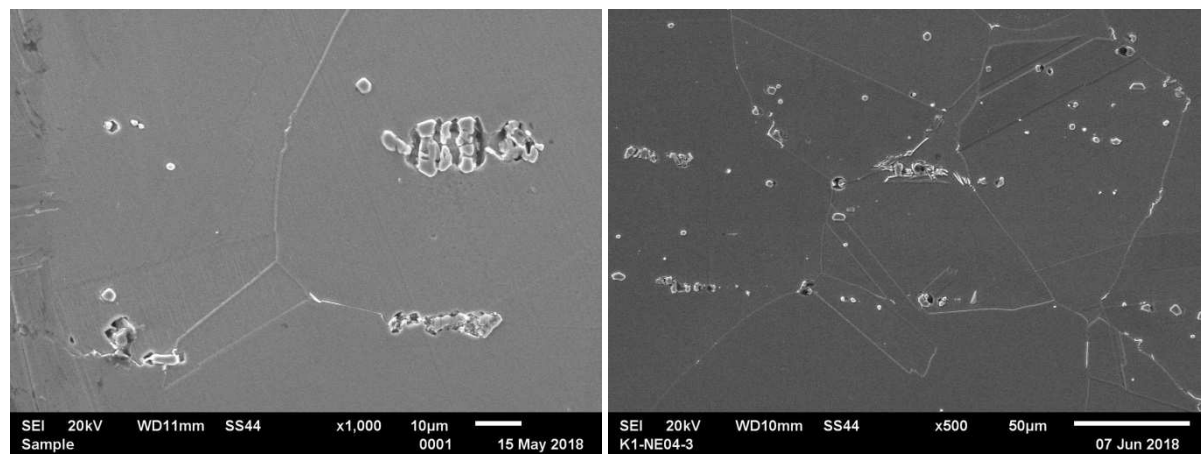

Fig. 1. Microstructure of HR6W alloy in the as-received condition.

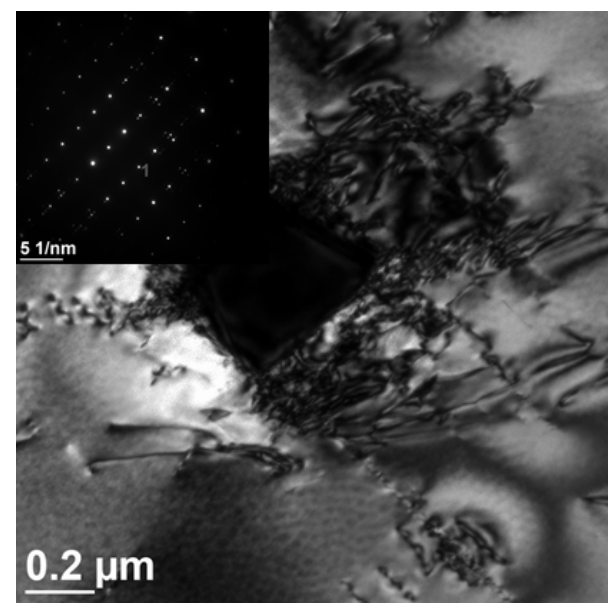

Fig. 2. Microstructure of primary TiN precipitate in HR6W alloy in the as-received condition, dark field.

According to $[5,10]$, in the as-received condition of the HR6W alloy (i.e. after solution heat treatment), there may also exist the primary $\mathrm{M}_{23} \mathrm{C}_{6}$ carbides in addition to the primary MX precipitates. However, precipitates of this type were not observed in the test alloy.

\subsection{Microstructure of test alloy after ageing}

The ageing of the test alloy has mainly contributed to intensive precipitation processes. In microstructure of the test alloy, numerous precipitates of varying morphologies were observed. At the grain and twin boundaries in the test alloy, the occurrence of globular $\mathrm{M}_{23} \mathrm{C}_{6}$ carbides and elongated Laves-phase precipitates were observed (Fig. 3-4). The grain boundaries in austenitic alloys are the first privileged place where secondary phases precipitate, as these are areas with increased energy and routes of easy diffusion. Next, the precipitation processes occur at the twin boundaries, both non-coherent and coherent. This results from the boundary energies, which are 0.7 and $0.2 \div 0.3$, respectively, of the largeangle boundary energy. The last place of the precipitate growth nucleation is the interior of grains, stacking faults, dislocations and slip bands $[6,11]$. In austenitic steels, the $\mathrm{M}_{23} \mathrm{C}_{6}$ carbides are the first secondary precipitates that occur in the structure of austenitic materials during ageing / operation [5, 6, 12]. According to [11], their impact on properties is determined not only by the amount of $\mathrm{M}_{23} \mathrm{C}_{6}$ particles precipitated at the grain boundaries, but also the shape of these particles. The lamellar-like $\mathrm{M}_{23} \mathrm{C}_{6}$ precipitates provide higher 
creep strength than steels with wedge-like precipitates, whereas the Laves-phase precipitates (Fig. 4b) in this type of alloy are considered to be favourable provided that the phase is relatively fine. The Laves-phase coarsening results in reduction of creep strength and crack resistance $[2,5,10,12]$. Inside the grains, numerous relatively fine secondary $\mathrm{M}_{23} \mathrm{C}_{6}$ carbide particles and Laves-phase precipitates were observed in addition to the primary MX (MC) precipitates. Titanium, niobium and addition of boron have a positive impact on relatively uniform distribution of dispersive $\mathrm{M}_{23} \mathrm{C}_{6}$ precipitates inside the grains of HR6W alloy. The $\mathrm{M}_{23} \mathrm{C}_{6}$ carbides precipitated inside the grains are coherent with the matrix and act as an efficient barrier to dislocation movement [2]. In creep-resistant alloys containing micro-addition of boron in their composition, boron atoms can substitute for some carbon atoms in $\mathrm{M}_{23} \mathrm{C}_{6}$ carbides. This results in the formation of $\mathrm{M}_{23}(\mathrm{C}, \mathrm{B})_{6}$ carboborides, which are more dispersive and have higher thermodynamic stability than $\mathrm{M}_{23} \mathrm{C}_{6}$ carbides. For a long time of service, $\mathrm{M}_{23}(\mathrm{C}, \mathrm{B})_{6}$ carboborides retain their finedispersion form, and thus have a favourable impact on creep resistance of these alloys [13]. Apart from the above-mentioned precipitates, the existence of compound complexes of TiN - Laves phase $-\mathrm{M}_{23} \mathrm{C}_{6}$ carbide precipitates was revealed inside the grains of the test alloy (Fig. 6), where the $\mathrm{M}_{23} \mathrm{C}_{6}$ particles and Laves phase nucleate heterogeneously on the TiN precipitate. The heterogeneous nucleation on TiN precipitates may be due to favourable crystalline relationships among the grids of precipitates and chemical composition fluctuations as well as higher nucleation activation energy at the intercrystalline boundaries compared to that inside the grain.

The compound complexes of precipitates in creep-resistant alloys were observed, among the others, by [14-16]. According to [17], the formation of compound complexes of AlN$\mathrm{NbX}$ in steel results from the fact that the system tends to reduce its internal energy and the nucleation at the intercrystalline border is easier than in the matrix. These authors also mention the favourable crystalline relationship among these precipitates. According to [15], the formation of compound complexes of $\mathrm{AlN}_{-3} \mathrm{M}_{23} \mathrm{C}_{6}$ and $\mathrm{AlN}-\mathrm{NbC}$ in $9-12 \% \mathrm{Cr}$ steel is accompanied by the occurrence of precipitate-depleted zones nearby these complexes and the increase in distance between these precipitates. Consequently, this leads to an uneven course of the creep process within the grain and its accelerated failure. In 9-12\% Cr steels, the NbX-VX complexes, referred to as the "V-wings", which act as an efficient barrier to dislocation movement resulting in the improvement of creep resistance, are also observed [16]. According to [5], ageing of the HR6W alloy also leads to the formation of dispersive secondary MX (MC) precipitates inside the grain. Such precipitates were not observed in the test alloy. In the HR6W alloy after ageing at $700^{\circ} \mathrm{C}$ for $10,000 \mathrm{~h}$, also no intermetallic sigma phase precipitates were revealed, which confirms the positive impact of the addition of tungsten on hindering and retarding the precipitation of this harmful intermetallic phase in the matrix [2]. 


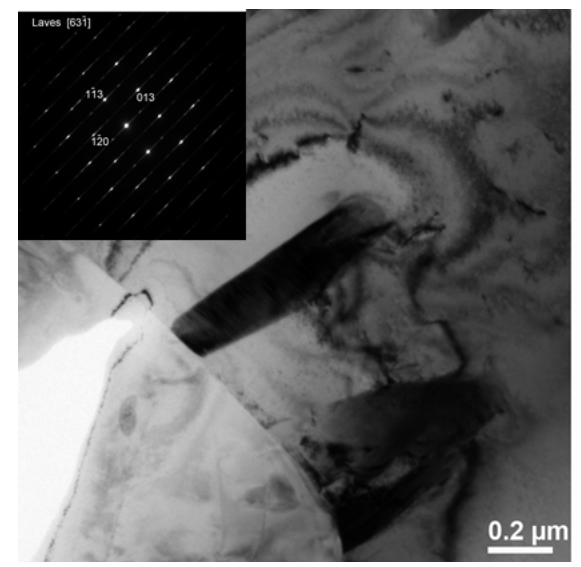

Fig.3. Laves-phase precipitates inside the grain, HR6W alloy after ageing
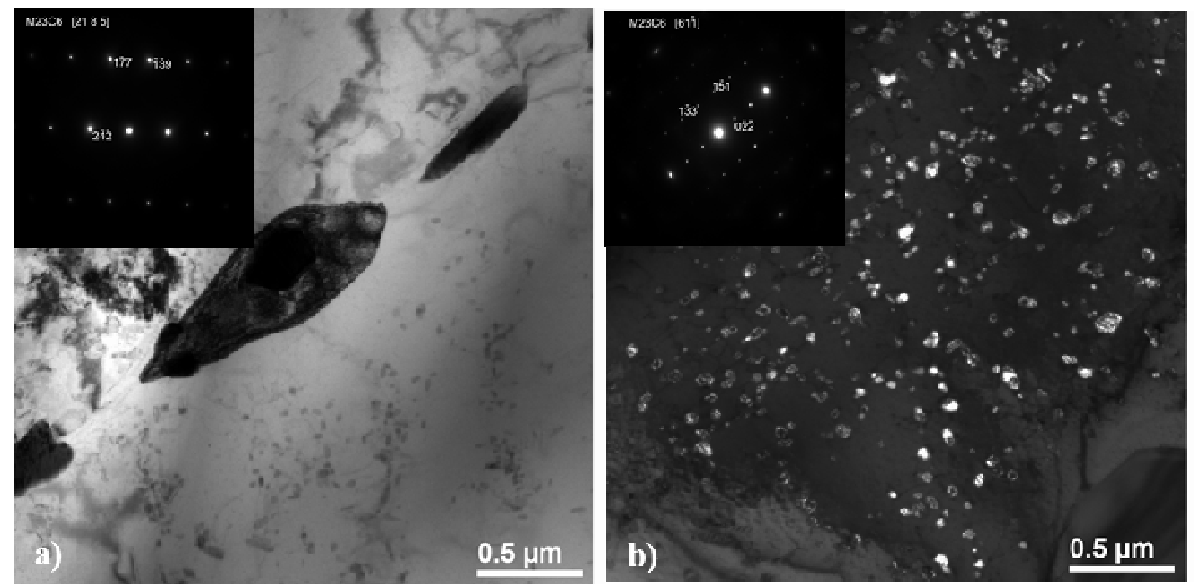

Fig.4. Morphology of $\mathrm{M}_{23} \mathrm{C}_{6}$ precipitates in the test alloy: a) at the grain boundary, b) inside the grain
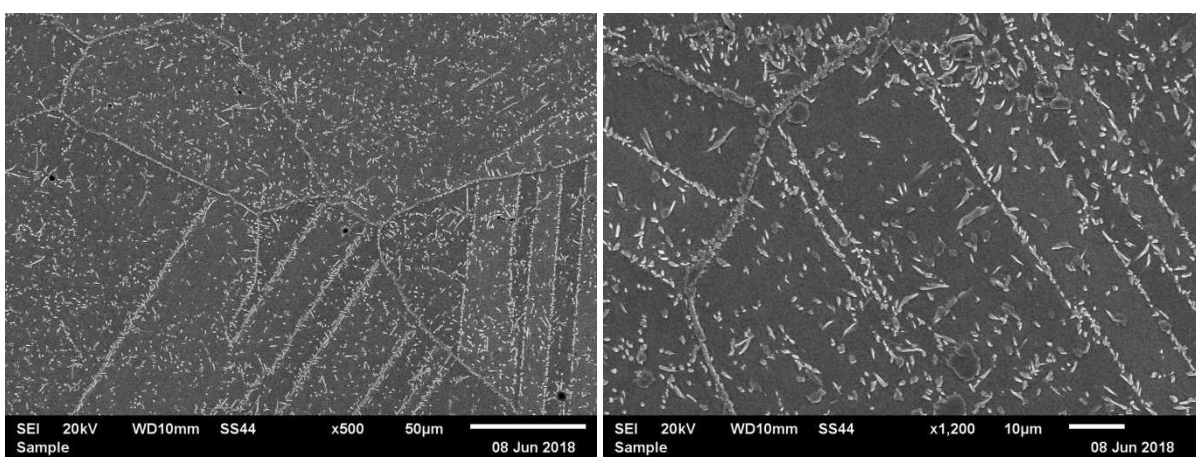

Fig.5 Microstructure of HR6W alloy after ageing at $700^{\circ} \mathrm{C}$ for $10,000 \mathrm{~h}$ 


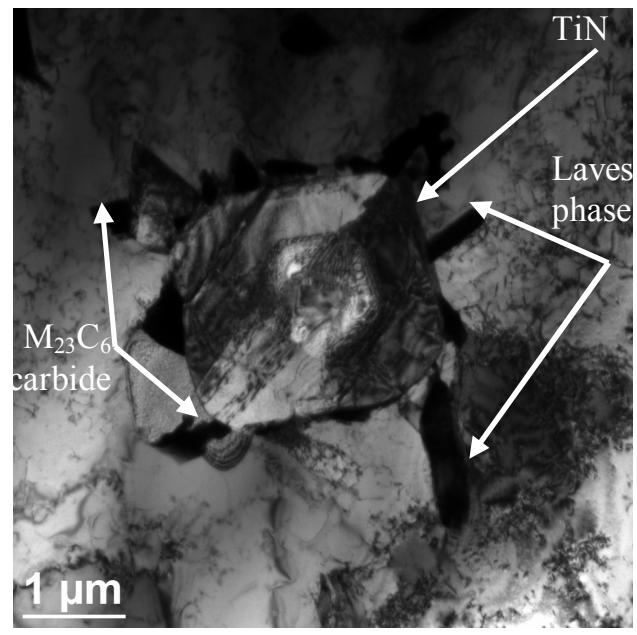

Fig.6 Compound complex of $\mathrm{TiN}_{-} \mathrm{M}_{23} \mathrm{C}_{6}$-Laves phase precipitates in $\mathrm{HR} 6 \mathrm{~W}$ alloy after the ageing

\section{Properties of HR6W alloy in the as-received condition and after ageing}

Similarly to austenitic steels, the HR6W alloy in the as-received condition is characterised by high plastic properties (A) at relatively low strength properties $\left(\mathrm{R}_{\mathrm{e}}, \mathrm{R}_{\mathrm{M}}\right)$ and hardness of approx. 185 HV10 (Fig. 7, 8). The properties of test alloy in the as-received condition are related to its structure (nickel austenite) and strengthening mechanism. The HR6W alloy is supplied after solution heat treatment, which translates into strengthening of the test material with the solution mechanism, which is realised mainly by tungsten atoms. As a substitution element, tungsten has the highest impact on increase in strength properties [18]. In austenitic alloys, the effect of grain size on strengthening does not play such an important role as for ferritic steels. Similarly to grain size, the effect of large primary precipitates on the properties of austenitic alloy is also relatively small. As shown by the calculations made for P91 steel, stress required for dislocation to bypass the precipitation using the Orowan mechanism is $16 \mathrm{MPa}$ for primary $\mathrm{NbC}$ carbide and $106 \mathrm{MPa}$ for secondary VX precipitate $[9,19]$. The ageing of HR6W alloy results in precipitation of numerous particles of varied morphologies, which contributes to the increase in strengthening with the precipitation mechanism. The precipitation strengthening of the test material takes place with a number of secondary $\mathrm{M}_{23} \mathrm{C}_{6}$ carbide particles, $\mathrm{MX}$ precipitates and Laves phase precipitates inside the grains. Precipitates inside the grain act as significant barriers that hinder and anchor free dislocations. At the grain boundaries in the test alloy, the precipitates of $\mathrm{M}_{23} \mathrm{C}_{6}$ carbides and Laves phase were revealed. The precipitation processes have contributed to visible increase in strength properties $\left(R_{e}\right.$ and $R_{m}$ increased by 65 and 32\%, respectively) and hardness (increased by 32\%), while reducing plastic properties (elongation A) (reduced by 38\%) compared to the as-received condition. In the test alloy, the $\mathrm{M}_{23} \mathrm{C}_{6}$ particles and Laves phase precipitated at the grain boundary hinder the grain slip, and thus affect the increase in creep resistance $[5,6,12]$. The positive impact of precipitates at the boundaries declines when particles form the so-called continuous grid of precipitates. The numerous particles at the grain boundaries in the test alloy (Fig. 5) are also likely to result in significant reduction in ductility (not studied in this paper) and a change in cracking mechanism from ductile to brittle, and may cause an increase in sensibility. The negative impact of numerous precipitates on the performance of creep-resistant austenitic alloys is particularly visible in HR3C steel [4, 20]. 


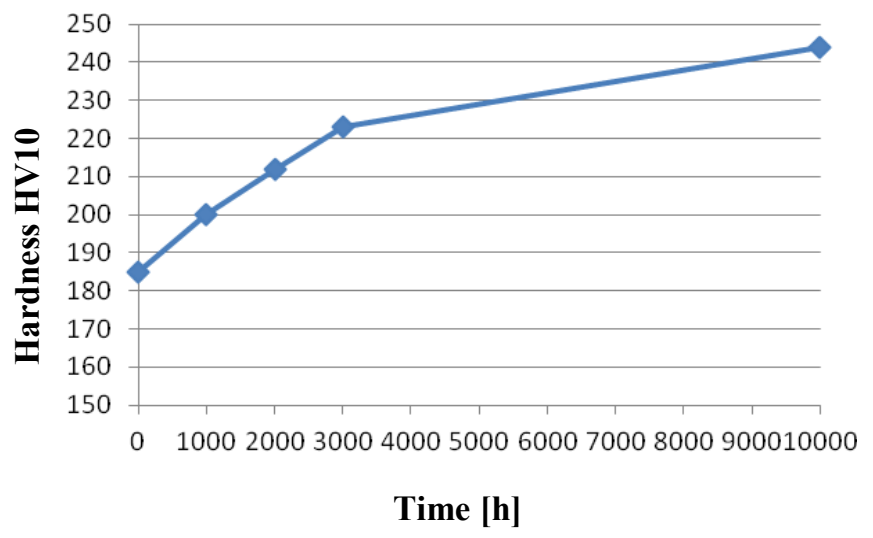

Fig. 7. Change in hardness of HR6W alloy during ageing at $700^{\circ} \mathrm{C}$

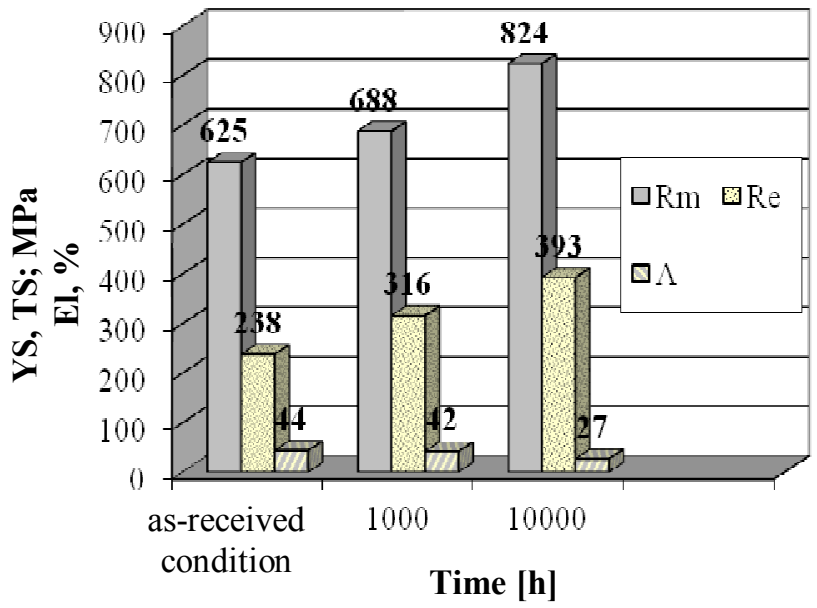

Fig. 8. Change in mechanical properties of HR6W alloy during ageing at $700^{\circ} \mathrm{C}$

\section{Summary}

The research involved HR6W nickel-base alloy, which is a construction material being implemented for system components in supercritical power units. The testing of HR6W alloy after ageing which simulates the operating conditions have revealed that this process results in significant increase in strengthening of the test alloy with the precipitation mechanism by secondary phase particles, i.e. $\mathrm{M}_{23} \mathrm{C}_{6}$ carbides and Laves phase. The increase in strengthening of HR6W alloy is directly reflected in the improvement in its properties $\left(R_{e}, R_{m}\right)$ with an acceptable reduction in plastic properties $(A)$, which still meet the required minimum. A similar increase was observed for hardness in the test alloy. The maintenance of high strength properties of HR6W alloy obtained at the initial stage of operation/ageing thon the stability of the fine-dispersive secondary particles precipitated inside the grains, but also on the solid solution strengthening.

\section{References}


1. Di Gianfrancesco: New Japanese materials for A-USC power, Materials for ultrasupercritical and advanced ultra-supercritical power plants, Eds. A. Di Gianfrancesco, pp. 423-466 (2016)

2. H. Semba, H. Okada, M. Igarashi: Creep properties and strengthening mechanisms in 23Cr-45Ni-7W (HR6W) alloy and Ni-base superalloys for $700^{\circ} \mathrm{C}$ A-USC boilers, Advances in Materials Technology for Fossil Power Plants Eds. R. Viswanthan, D. Gandy, K. Coleman, Florida, pp.168-184 (2008)

3. A. Hernas, J. Dobrzański, J. Pasternak, S. Fudali: Characteristics of the newgeneration materials for the power industry (2015)

4. A. Zieliński, M. Sroka, A. Hernas, M. Kremzer: The effect of long-term impact of elevated temperature on changes in microstructure and mechanical properties of HR3C steel, Archives of Metallurgy and Materials, 2, 61, pp. 761-766 (2016)

5. J. Yan, Y. Gu i J. Lu: On precipitates in $\mathrm{Fe}-\mathrm{Ni}$ base alloys used for USC boilers, Materials Science and Technology, 4, 31, pp. 389-399 (2015)

6. T. Sourmail: Precipitation in creep resistant austenitic stainless steels, Materials Science and Technology, 1, 17, pp. 1-14 (2001)

7. M. Sroka, A. Zieliński, A. Hernas, Z. Kania, R. Rozmus, T. Tański, A. Śliwa: The effect of long-term impact of elevated temperature on changes in the microstructure of Inconel 740H alloy, Metalurgija, 333, 56, pp. 333-336 (2017)

8. A. Zieliński, J. Dobrzański, H. Purzyńska, G. Golański: Properties, structure and creep resistance of austenitic steel Super 304H, Materials Testing, 859, 57, pp. 859-865 (2015)

9. J. Erneman, M. Schwind, H. O. Andren, J. O. Nilsson: The evolution of primary and secondary niobium carbonitrides in AISI 347 stainless steel during manufacturing and long-term ageing, Acta Materialia, 54, , pp. 67-76 (2006)

10. T. Tokairin, K. V. Dahl, H. K. Danielsen, F.B. Grumsen, T. Sato, J. Hald: Investigation on long-term creep rupture properties and microstructure stability of $\mathrm{Fe}-\mathrm{Ni}$ based alloy $\mathrm{Ni}-23 \mathrm{Cr}-7 \mathrm{~W}$ at $700^{\circ} \mathrm{C}$, Materials Science and Engineering A, 565, pp. 285-291 (2013)

11. B. Weiss, R. Stickler: Phase instabilities during high temperature exposure of 316 austenitic stainless steel, Metallurgical and Materials Transactions B, 3, pp. 851-866 (1972)

12. K.H. Lo, C.H. Shek, J.K.L Lai.: Recent developments in stainless steels, Materials Science and Engineering R, 4-6, 65, pp. 39-104 (2009)

13. F. Abe: New martensitic steels, Materials for ultra-supercritical and advanced ultrasupercritical power plants, pp. 323-374 (2016)

14. P. Jamrozik, M. Sozańska: Precipitation processes in HR6W alloy after long-term ageing, Solid State Phenomena, 246, pp. 33-38 (2016)

15. H. Naoi, M. Ohgami, X. Liu, T. Fujita: Effects of aluminum content on the mechanical properties of a $9 \mathrm{Cr}-0.5 \mathrm{Mo}-1.8 \mathrm{~W}$ Steel, Metallurgical and Materials Transactions A, 5, 28, pp. 1195-1203 (1997)

16. K. Hamada, K. Tokun, Y. Tomita. H. Mabuchi, K. Okamoto: Effects of precipitate shape on high temperature strength of modified 9Cr-1 Mo steels, ISIJ International, 1, 35, pp. 86-91 (1995)

17. M.J. Leap, E.L. Brown: Crystallography of duplex AlN-Nb(C,N) precipitates in $0.2 \%$ C steel, Scripta Materialia, 47, pp. 793-797 (2002)

18. L.P. Karjalainen, T. Taulavuori, M. Sellman, A. Kyröläinen: Some strengthening methods for austenitic stainless steels, Materials Technology, 2016, pp. 404-412.

19. H. Magnusson, R. Sandstrom: Influence of aluminium on creep strength of $9-12 \% \mathrm{Cr}$ steels, Materials Science and Engineering, 527, pp. 118-125 (2009)

20. G. Golański, C. Kolan, A. Zieliński, K. Klimaszewska, A. Merda, M. Sroka, J. Kłosowicz: Microstructure and mechanical properties of HR3C austenitic steel after service, Archives of Materials Science and Engineering, 2, 81, pp. 62-67 (2016) 